\title{
The Phytoremediation Technique for Cleaning up Contaminated Soil By Amaranthus sp.
}

\section{Parisa Ziarati ${ }^{1 *}$ and Somaye Alaedini ${ }^{2}$}

${ }^{1}$ Department of Medicinal Chemistry, Pharmaceutical Sciences Branch, Islamic Azad University (IAUPS), Tehran, Iran ${ }^{2}$ Pharmaceutical Sciences Branch, Islamic Azad University (IAUPS), Tehran, Iran

\begin{abstract}
Phytoremediation is the biotechnological application of plants to detoxify pollutants, and is an ideal and modern technique for environmental clean-up. Regarding the vast industrial waste materials and sewages from a lot factories and different chemical fertilizers and pesticides have caused contamination of soils in Tehran, potential ability of Amaranthus to phytoextract lead, cadmium, copper, nickel and zinc was investigated and Compare of the soil $\mathrm{pH}$ and the phytoextraction rate based on different growth stages of the plant. Determine metal transfer factors from soil (TFS) of Amaranthus and the effect of adding black and green tea leaves in soil and the metal transfer factors have been studied. Results indicated that the younger plants have more potential to uptake and concentrate the studied heavy metals than the older ones and the uptake rate is significantly affected by the plant accumulation and the soil $\mathrm{pH}$. The best results for uptake of Lead was in the soil with $\mathrm{pH}=6.5$ among different samples and in this $\mathrm{pH}$ translocation factor was the highest by 45 days grown of plants while the best result of Cadmium phytoextract was in pH of soil 6.3 by 35 days growth of plants.
\end{abstract}

The maximum Zinc, Copper and Nickel uptake rate was in $\mathrm{pH}=6.1$ and by 30 day grown Amaranth. Regarding the results of the present study, it is recommended to study more on the species belong to other plant families that have potential ability to hyper accumulate heavy metals especially the inedible plants.

Keywords: Phytoremediation; phytoextraction; Amaranthus; Cadmium; Contaminated soil; Lead.

\section{Introduction}

According to a report released by a U.S. environmental action group, the world's most polluted places threaten the health of more than 10 million people in many countries [1]. Most of the soil contaminants can be removed by many other physical methods but the heavy metal pollution of vast cultivated land areas are a serious threat to the agricultural biology. During the industrial developments, the level of toxic heavy metals has been increased in soil and has caused environmental contamination especially in capital city Tehran. According to a report from Department of the Environment Tehran, I.R. Iran in July 2005, some significant sources of Lead and cadmium are: Nickel-Cadmium Batteries, Cadmium pigments, Cadmium stabilizers, Cadmium Coating, fossil fuels, cement, phosphorous fertilizers, Lead batteries, Glasses \& ceramic industries, paint manufacturers, Cadmium electronic compounds, Metal plating, Factories with the process of extraction, production and concentration of Lead ore, Industrial wastewater, solid waste and Municipal waste waters [2]. Therefore, the vast industrial waste materials and sewages from a lot factories and different chemical fertilizers and pesticides in Tehran have caused contamination of soils. Heavy metal bioaccumulation in food chain could be highly dangerous to human health and on the other hand preventing heavy metal pollution is critical because cleaning contaminated soils is extremely expensive and difficult [3].

Plants are ideal agents for soil and water remediation because of their unique genetic, biochemical and physiological features. Phytoremediation is the most emerging field of environmental biotechnology. The plant roots have natural ability to absorb the heavy metals of the soil, behaving as natural phytoremediates.

Phytoremediation consists of six different plant-based technologies that include: Depending on the contaminants, the site conditions, the level of clean-up required, and the types of plants, phytoremediation technology can be used for containment: phytoimmobilization and phytostabilization, or removal: phytoextraction and phytovolatilization [4]. The pollutants remain absorbed in or adsorbed to the roots. Rhizofiltration, which involves the use of plants to clean various aquatic environments; phytostabilization, where plants are used to stabilize rather than clean contaminated soil; phytovolatilization, which involves the use of plants to extract certain metals from soil and then release them into the atmosphere through volatilization; and phytoextraction, where plants absorb metals from soil and translocate them to the harvestable shoots where they accumulate. Although plants show some ability to reduce the hazards of organic pollutants [5-9], the greatest progress in phytoremediation has been made with metals [10-12]. At least 45 families have been identified to hyper accumulate heavy metals including Brassicaceae, Amaranthaceae and Scrophulariaceae [13]. The present study was undertaken in view of providing an impeccable hypothesis that Amaranth (Amaranthus sp.) may probably be employed as a potent phytoremediation of heavy metals from polluted soils. It belongs to Amaranthaceae family and can be cultivated or grown easily in contaminated soils and a possible use for the sanitation of sludge and waste substrates. The aims of this research were to:

1. Determining Amaranthus for Cleaning up Contaminated Soil

*Corresponding author: Parisa Ziarati, Islamic Azad University, Pharmaceutical Sciences Branch (IAUPS), Faculty of Pharmacy, Toxicogenomics lab, No 99 Yakhchal, Gholhak, Dr. Shariati, Tehran, Iran, Tel: +98-21-22600037; Fax: +98-2122633986; E-mail: ziarati.p@iaups.ac.ir

Received December 12, 2013; Accepted January 21, 2014; Published January 24, 2014

Citation: Ziarati P, Alaedini S (2014) The Phytoremediation Technique for Cleaning up Contaminated Soil By Amaranthus sp. J Environ Anal Toxicol 4: 208. doi: 10.4172/2161-0525.1000208

Copyright: $(2014$ Ziarati $P$, et al. This is an open-access article distributed under the terms of the Creative Commons Attribution License, which permits unrestricted use, distribution, and reproduction in any medium, provided the original author and source are credited. 
and their potential ability of to phytoextract different metals (Nickel, Copper, Zinc, Lead and Cadmium).

2. Compare of the soil $\mathrm{pH}$ and the phytoextraction rate based on different growth stages of the plant.

3. Determine metal transfer factors from soil (TFS) of Amaranthus.

4. Study the effect of adding black and green tea leaves in soil and the metal transfer factors.

The aims of this research were to determine the relationship between the soil $\mathrm{pH}$ and the phytoextraction rate based on different growth stages of the plant and the potential ability of Amaranth to phytoextract different metals (Zinc, Copper, Lead, Cadmium and Nickel).

\section{Material and Methods}

\section{Soil sampling}

A composite soil sample was collected from depth of $0-35 \mathrm{~cm}$ from a yard in the center of Tehran in order to simulate the conditions of soils in the contaminated lands with industrial sewages. 30, 15, 10, 5, 10, 5, 5, 30 and $30 \mathrm{mmol} / \mathrm{L}$ of $\mathrm{Pb}\left(\mathrm{NO}_{3}\right)_{2}, \mathrm{Cd}\left(\mathrm{NO}_{3}\right)_{2}, \mathrm{ZnSO}_{4}, \mathrm{Zn}\left(\mathrm{NO}_{3}\right)_{2}, \mathrm{Ni}\left(\mathrm{NO}_{3}\right)_{2}$, $\mathrm{Ni}_{3}\left(\mathrm{PO}_{4}\right)_{2}, \mathrm{NiCl}_{2}, \mathrm{CaHPO}_{4}$ and $\mathrm{K}_{2} \mathrm{SO}_{4}$ respectively and $200 \mathrm{~g}$ of dried black and green tea leaves (ratio 3:1) were added. At the beginning of study, soil profile characteristics were observed and recorded by a packet penetrometer (Cl-700A, soil Test Inc., USA). Soil samples were mixed, homogenized and separated into three parts, $1 / 3$ of each samples was air-dried and pass through a $2 \mathrm{~mm}$ sieve in order to determine $\mathrm{p}$ and $\mathrm{k}$ content, $\mathrm{pH}$ and electrical conductivity and particle-size distribution. The other $2 / 3$ was passed through a $2 \mathrm{~mm}$ sieve without drying and $1 / 3$ of it used to determine heavy metals concentration by Atomic Absorption Spectroscopy (AAS) after digestion with aqua-region. The samples were analyzed by an Atomic Absorption Spectrophotometer Model AA-6200 (Shimadzu, Japan) using an air-acetylene flame for heavy metals- $\mathrm{Pb}, \mathrm{Cd}, \mathrm{Cr}, \mathrm{Ni}, \mathrm{Zn}$ and $\mathrm{Cu}$, using at least two standard solutions for each metal. All necessary precautions were taken to avoid any possible contamination of the sample as per the AOAC guidelines.

The last port used to determine nitrate and ammonium $2 \mathrm{M} \mathrm{KCl}$ extraction followed by determination using flow injection method. All the soil data are expressed on a dry basis. The soil by different $\mathrm{pH}$ put into eight vases and Amaranth samples were grown in six examined soils and no plants were grown in two others as they have been considered as control group in soils, the same procedure in the other reports of scientists who have investigated the effects of soil acidification on $\mathrm{Zn}$ and Cd phytoextraction [14]. As soil acidification might cause some negative side effects such as increasing solubility of some toxic metals and leaching them into the groundwater and creating another environmental risk. Therefore, at the beginning of study, we tried to control $\mathrm{pH}$ at the range of 5.9 up to 6.9 in samples of soils.

\section{Sampling method}

Different parts: shoots and roots of 200 greenhouse -grown Amaranth plants in the same situation were studied in spring and summer 2013. Samples were watered each day by tap water (Tehran tap water). The studied samples were managed by the same light situation and some circumstances in order to be compared with each other due to determine the ability of Amaranth in phytoextraction of Lead, Zinc, Cadmium, Copper, and Nickel from soil.

The soil by different pH (5.9 up to 6.9) put into 69 vases) $65 \mathrm{~cm}$ $\mathrm{x} 45 \mathrm{~cm}$ ) and samples were grown in eight examined soils and no plants were grown in two others as they have been considered as control group in soils, as the same procedure in the other reports of scientists who have investigated the effects of soil acidification on Cadmium phytoextraction [14]. As soil acidification might cause some negative side effects such as increasing solubility of some toxic metals and leaching them into the groundwater and creating another environmental risk. Therefore, at the beginning of study, we tried to control $\mathrm{pH}$ at the range of 5.9 up to 6.9 in samples of soils.

All samples were watered each day by tap water (Tehran tap water). The studied samples were managed by the same light situation and some other factors in the Toxicogenomics laboratory in Pharmaceutical Sciences Branch, Azad University and some circumstances in order to be compared with each other due to determine the ability of Amaranthus sp. for potential ability of Lead, Copper, Nickel, Zinc and Cadmium phytoextraction from soil.

Physical and chemical properties and concentrations of heavy metals in soils before and after adding Cadmium, Nickel, Lead, Zinc, and Copper, and also, after the growth period measured. In order to assess amount of heavy metals transfer from soil to plant (shoot and root), translocation factor was determined by dividing metal concentration at shoot by its concentration at root [15]. The ratios were higher than one it was considered as suitability of plant at that condition for use in phytoremediation.

\section{Results}

Chemical extraction of the soil profile before adding specified amounts of heavy metals is shown in the Table 1. Data is averages of the profiles.

Plant availability of certain heavy metals depends on soil properties such as soil $\mathrm{pH}$ and contains exchange capacity and on the distribution of metals among several soil fractions. Results indicated that the rate of heavy metals uptake by this plant is significantly affected by $\mathrm{pH}$ $(\mathrm{p}<0.02)$. The fractionation of $\mathrm{Pb}, \mathrm{Zn}, \mathrm{Ni}, \mathrm{Cu}$, and $\mathrm{Cd}$ in control soil and in soil treated by Amaranth is shown in Table 2.

Younger plants had more potential to uptake and concentrate heavy metals than older ones. Translocation factor in all conditions were higher than one which indicates that metal concentrations in shoots were higher than roots and the plant Amaranth is suitable for phytoremediation.

The best results for uptake of Lead was in the soil with $\mathrm{pH}=6.5$ among different samples and in this $\mathrm{pH}$ translocation factor was the highest by 45 days grown of plants while the best result of Cadmium phytoextract was in $\mathrm{pH}$ of soil 6.3 by 35 days growth of plants.

The maximum Zinc, Copper and Nickel uptake rate was in $\mathrm{pH}=6.1$ and by 30 day grown Amaranth (Table 3).

As expected the additional number of Amaranth plants cultivated in sample soils increased the potion of $\mathrm{Pb}, \mathrm{Cd}, \mathrm{Zn}$, and $\mathrm{Ni}$. The heavy metals uptake rate by this plant is significantly affected by number of plant cultivated as for lead uptake ( $\mathrm{p}<0.03$ ) while for $\mathrm{Cd}$ and copper the p-value was less than 0.01 . The percentage of heavy metals uptake by this plant has been demonstrated in Figure 1 due to number of harvesting in

\begin{tabular}{|c|c|c|c|c|}
\hline $\begin{array}{c}\text { Layer } \\
\text { (depth } \mathbf{~ c m})\end{array}$ & $\mathbf{p H}\left(\mathbf{H}_{2} \mathbf{O}\right)$ & $\begin{array}{c}\text { Electrical conductivity } \\
\mathbf{d S} / \mathbf{c m} \mathbf{1 : 1}\end{array}$ & $\begin{array}{c}\mathbf{N O}_{3}-\mathbf{N} \\
\mathbf{m g} / \mathbf{k g ~ D W}\end{array}$ & $\begin{array}{c}\mathbf{N H}_{4}-\mathbf{N} \\
\mathbf{m g} / \mathbf{k g ~ D W}\end{array}$ \\
\hline $1(0-15)$ & 6.4 & 0.44 & 60.9 & 9.65 \\
\hline $2(15-35)$ & 6.5 & 0.23 & 20.5 & 8.30 \\
\hline
\end{tabular}

Table 1: Chemical characteristics of the soil profile at the studied vases (before adding chemical substances and pre growing of Amaranthus). 
Citation: Ziarati P, Alaedini S (2014) The Phytoremediation Technique for Cleaning up Contaminated Soil By Amaranthus sp. J Environ Anal Toxicol 4: 208. doi: 10.4172/2161-0525.1000208

Page 3 of 4

\begin{tabular}{|c|c|c|c|c|c|c|c|c|}
\hline Soil samples & $\mathrm{S}_{1}$ & $\mathrm{~S}_{2}$ & $\mathbf{S}_{3}$ & $\mathrm{~S}_{4}$ & $\mathbf{S}_{5}$ & $S_{6}$ & $\mathrm{~S}_{7}$ & $\mathbf{S}_{8}$ \\
\hline First Crop harvest & Amaranthus & Amaranthus & Amaranthus & Amaranthus & Amaranthus & Amaranthus & ------- & ------- \\
\hline Growth period & 30 days & 30 days & 35 days & 45 days & 45 days & 55 days & ------- & ------ \\
\hline Soil type $(0-15 \mathrm{~cm})$ pH 1:1 & 5.9 & 6.1 & 6.3 & 6.5 & 6.7 & 6.9 & 6.7 & 6.9 \\
\hline EC $1: 1 \mathrm{dS} / \mathrm{m}$ & 0.32 & 0.48 & 0.45 & 0.52 & 0.38 & 0.44 & 0.46 & 0.47 \\
\hline $\mathrm{NO} 3-\mathrm{N}$ mg/kg DW & 21.9 & 25.1 & 22.4 & 28.0 & 39.5 & 33.3 & 56.3 & 57.8 \\
\hline NH4-N mg/kg DW & 2.66 & 2.72 & 2.48 & 3.16 & 3.11 & 2.72 & 4.83 & 5.25 \\
\hline$\% \mathrm{~Pb}$ uptake & 27.5 & 27.7 & 29.1 & 32.1 & 28.6 & 27.9 & ---- & ---- \\
\hline$\%$ Cd uptake & 12.9 & 13.2 & 14.3 & 14.1 & 14.1 & 13.5 & ---- & ---- \\
\hline$\%$ Zn uptake & 9.42 & 10.24 & 9.82 & 8.43 & 8.50 & 8.11 & --- & ---- \\
\hline$\%$ Ni uptake & 6.36 & 7.11 & 6.53 & 5.18 & 5.98 & 5.99 & ----- & ----- \\
\hline$\%$ Cuuptake & 11.95 & 11.55 & 11.06 & 10.76 & 10.62 & 10.20 & ---- & $-\cdots--$ \\
\hline
\end{tabular}

Table 2: The characteristics of soil samples and their potential of uptake heavy metals comparing with their $\mathrm{pH}$.

\begin{tabular}{|c|c|c|c|c|c|}
\hline $\begin{array}{c}\text { No. } \\
\text { Harvest }\end{array}$ & \% Pb uptake & \% Cd uptake & \% Zn uptake & \% Ni uptake & \% Cu uptake \\
\hline 1 & 32.1 & 14.1 & 8.43 & 5.18 & 10.76 \\
\hline 2 & 33.6 & 14.6 & 10.22 & 6.30 & 12.46 \\
\hline 3 & 35.1 & 14.9 & 11.92 & 7.23 & 13.09 \\
\hline
\end{tabular}

Table 3: Amaranth potential uptake ability of heavy metals in soil by $\mathrm{pH} 6.5$ comparing by number of harvesting

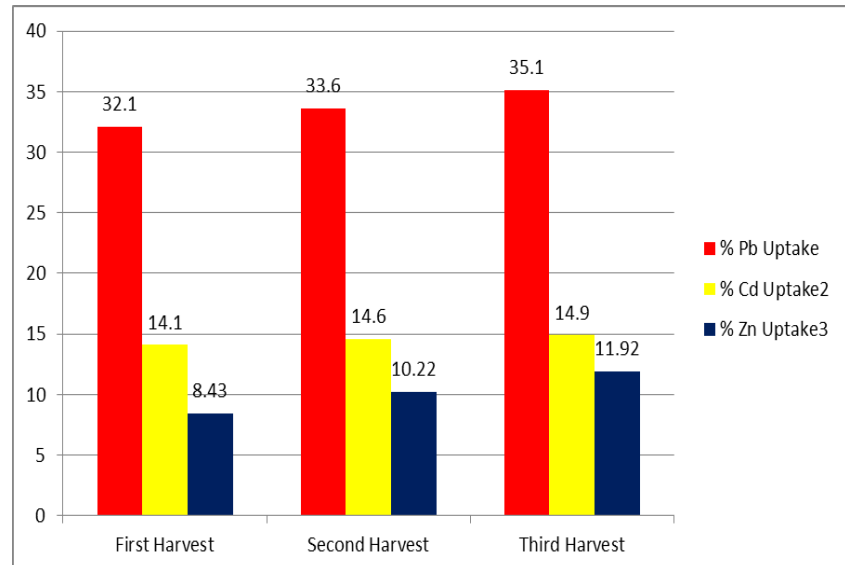

Figure 1: Amaranth potential uptake ability of Lead, Cadmium and Zinc in soil (Tea leaves added) with $\mathrm{pH} 6.5$ comparing by number of harvesting.

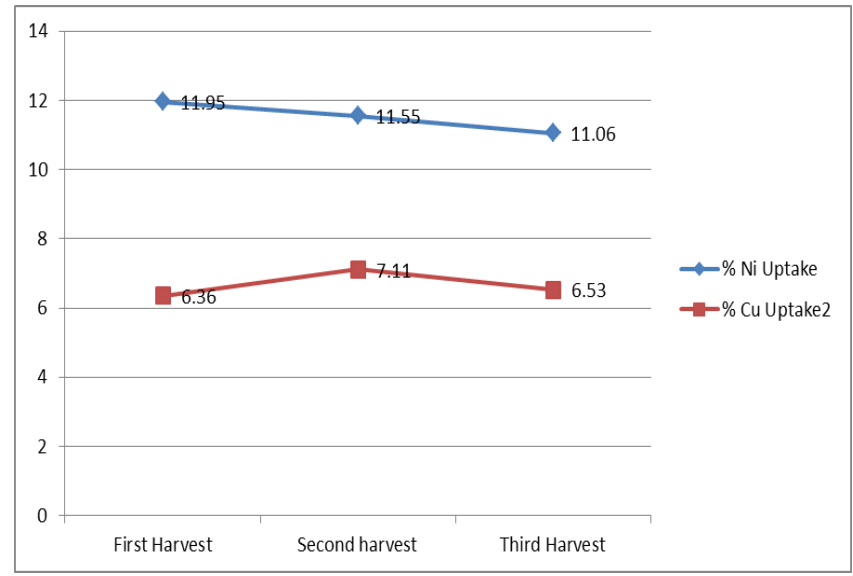

Figure 2: Amaranth potential uptake ability of Nickel and Copper in soil (Tea leaves added) with $\mathrm{pH} 6.5$ comparing by number of harvesting. soil $\mathrm{pH} 6.5$ which shows that Translocation factor in all conditions were higher than one which indicates that metal concentrations in shoots were higher than roots and the plant is suitable for phytoremediation and the heavy metals uptake rate by this plant is significantly affected by time of growing plant as for lead uptake $(\mathrm{p}<0.01)$ while for $\mathrm{Cd}$ and Nickel the $p$-value was less than 0.03. In Figure 2 it has been indicated that younger plants had more potential to uptake Nickel and Copper and concentrate them than older plants as the translocation factor in third harvest and after 45 days conditions were decreased which indicates that metal concentrations in shoots were higher than roots and the plant is suitable for phytoremediation. A highly significant, although low, positive correlation $(\mathrm{r}=0.51, \mathrm{p}=0.01, \mathrm{n}=200)$ was found between Lead and Cadmium and Zinc of the greenhouse-grown Amaranth, compared to a non-significant and much lower correlation between the two other heavy metals: Nickel and Copper.

\section{Conclusion}

It is obvious that many countries throughout the world such as Iran and other developing countries that are grappling with the issue of contaminated environments need a low cost and effective strategy $[8,9]$. By determining the characteristics that influence environmental contamination by heavy metals especially Lead and Cadmium, scientists will be able to map high and low risks areas of contamination. Harvesting the certain plants to accumulate, up taken and translocating metals from roots to shoots can remove toxic and heavy metals from the soil and preventing vegetables, crops and other products to absorb them. This technology is not only low cost but also applied strategy to agriculture and to environmental problems.

The results of this research concluded that Amaranth in the soil which consisted of dried black and green tea leaves had suitable ability for phytoremediation by phytoextraction method and transmitting more Lead and Cadmium in $\mathrm{pH}$ 6.3-6.5 after 35-45 days of growth.

Regarding the results of the present study, it is recommended to study more on the species belong to other plant families that have potential ability to hyperaccumulate heavy metals especially the inedible plants.

\section{References}

1. Environment News Service (ENS) (2006) New York, October

2. Department of The Environment Tehran (2005) Review of scientific information focusing especially on long range environmental transport. The Islamic Republic of Iran.

3. (2000) Heavy Metal Soil Contamination, Soil Quality-Urban Technical Note No.3, United States Department of Agriculture, Natural Resources Conversation Service.

4. Padmavathiamma PK, Li LY (2007) Phytoremediation Technology: Hyperaccumulation Metals in Plants. Water Air Soil Pollut 184:105-126. 
Citation: Ziarati P, Alaedini S (2014) The Phytoremediation Technique for Cleaning up Contaminated Soil By Amaranthus sp. J Environ Anal Toxicol 4: 208. doi: 10.4172/2161-0525.1000208

Page 4 of 4

5. Cunningham SD, Berti WR, Huang JW (1995) Phytoremediation of contaminated soils. Trends in Biotechnology 13: 393-397.

6. Gordon M, Choe N, Duffy J, Ekuan G, Heilman P, et al. (1998) Phytoremediation of trichloroethylene with hybrid poplars. Environ Health Perspect 106 Suppl 4: 1001-1004.

7. Carman EP, Crossman TL, Gatliff EG (1998) Phytoremediation of no. 2 fuel oilcontaminated soil. Journal of Soil Contamination 7: 455-466.

8. Manshadi M, Ziarati P, Ahmadi M, Fekri K (2013) Greenhouse Study of Cadmium and Lead phytoextraction by five Pelargonium spices. Intl J Farm \& Alli Sci 2: 665-669.

9. Ahmadi M, Ziarati P, Manshadi M, Asgarpanah J, Mousavi Z (2013) The Phytoremediation Technique for Cleaning Up Contaminated Soil by Geranium (Pelargonium roseum). Intl J Farm Alli Sci 2: 477-481.

10. Salt DE, Blaylock M, Kumar NP, Dushenkov V, Ensley BD, et al. (1995) Phytoremediation: a novel strategy for the removal of toxic metals from the environment using plants. Biotechnology (N Y) 13: 468-474.

11. Watanabe ME (1997) Phytoremediation on the brink of commericialization. Environ Sci Technol 31: 182A-6A.

12. Blaylock MJ, Huang JW (2000) Phytoextraction of metals. In: Raskin I, Ensley BD edn. Phytoremediation of toxic metals: using plants to clean-up the environment. New York, John Wiley \& Sons, Inc. 53-70.

13. Jadia CD, Fulekar MH (2009) Phytoremediation of heavy metals: Recent Techniques. African Journal of Biotechnology 8: 921-928.

14. Moteshare ZB, Savaghebi-Firozabadi GhR, Alikhani HA, Hosseini MH (2008) Effect of Sunflower and Amaranthus Culture and Application of Inoculants on Phytoremediation of the Soils Contaminated with Cadmium. AmericanEurasian J Agric Environ Sci 4: 93-103.

15. Marchiol L, Assolari S, Sacco P, Zerbi G (2004) Phytoextraction of heavy metals by canola (Brassica napus) and radish (Raphanus sativus) grown on multicontaminated soil. Environ Pollut 132: 21-27. 